\title{
The effects of trabecular-bone loading variables on the surface signaling potential for bone remodeling and adaptation
}

Citation for published version (APA):

Ruimerman, R., Rietbergen, van, B., Hilbers, P. A. J., \& Huiskes, R. (2005). The effects of trabecular-bone loading variables on the surface signaling potential for bone remodeling and adaptation. Annals of Biomedical Engineering, 33(1), 71-78. https://doi.org/10.1007/s10439-005-8964-9

DOI:

10.1007/s10439-005-8964-9

Document status and date:

Published: 01/01/2005

Document Version:

Publisher's PDF, also known as Version of Record (includes final page, issue and volume numbers)

Please check the document version of this publication:

- A submitted manuscript is the version of the article upon submission and before peer-review. There can be important differences between the submitted version and the official published version of record. People interested in the research are advised to contact the author for the final version of the publication, or visit the $\mathrm{DOI}$ to the publisher's website.

- The final author version and the galley proof are versions of the publication after peer review.

- The final published version features the final layout of the paper including the volume, issue and page numbers.

Link to publication

\section{General rights}

Copyright and moral rights for the publications made accessible in the public portal are retained by the authors and/or other copyright owners and it is a condition of accessing publications that users recognise and abide by the legal requirements associated with these rights.

- Users may download and print one copy of any publication from the public portal for the purpose of private study or research.

- You may not further distribute the material or use it for any profit-making activity or commercial gain

- You may freely distribute the URL identifying the publication in the public portal.

If the publication is distributed under the terms of Article 25fa of the Dutch Copyright Act, indicated by the "Taverne" license above, please follow below link for the End User Agreement:

www.tue.nl/taverne

Take down policy

If you believe that this document breaches copyright please contact us at:

openaccess@tue.nl

providing details and we will investigate your claim. 


\title{
The Effects of Trabecular-Bone Loading Variables on the Surface Signaling Potential for Bone Remodeling and Adaptation
}

\author{
R. Ruimerman, B. VAN RiETBERGEN, P. HiLbERS, and R. Huiskes \\ Department of Biomedical Engineering, Eindhoven University of Technology, The Netherlands
}

(Received 28 January 2004; accepted 16 August 2004)

\begin{abstract}
It is widely believed that mechanical forces affect trabecular bone structure and orientation. The cellular mechanisms involved in this relationship, however, are poorly understood. In earlier work we developed a theoretical, computational framework, coupling bone-cell metabolic expressions to the local mechanical effects of external bone loading. This theory is based on the assumption that osteocytes within the bone tissue control the recruitment of bone-resorbing osteoclasts and bone-forming osteoblasts, by sending strain-energy-density (SED) related signals to trabecular surfaces through the osteocytic, canalicular network. The theory explains the known morphological effects of external bone-loading variations in magnitude and frequency. It also explains the development of osteoporosis, as an effect of increased osteoclast resorption due to estrogen deficiency in postmenopausal women, and to reduced physical activity levels in general. However, the theory uses lumped variables to represent the mechanisms of osteocyte mechano-sensing and signaling. The question is whether these mechanisms could not be specified in a more realistic way. On the one hand, anabolic osteocyte signals might be triggered by the local mechanical loading variables they experience directly, as we assumed in our original theory. On the other hand, osteocyte signals might be triggered by fluid flow in the osteocytic network at large, as was suggested by others. For that purpose we compared the effects of $S E D$, maximal principal strain and volumetric strain as representing local loading variables, to their spatial gradients on the morphological predictions of our computational model. We found that, in concept, they all produced reasonable trabecular structures. However, the predicted trabecular morphologies based on $S E D$ as the triggering variable were more realistic in dimensions and relevant metabolic parameters.
\end{abstract}

Keywords-Trabecular bone, Modeling, Remodeling, Mechanical adaptation, Computer simulation.

\section{INTRODUCTION}

Trabecular bone is continuously renewed by boneresorbing osteoclasts and bone-forming osteoblasts. In growth or adaptation they change the shape of trabecular morphology and adapt it to external loading direction and

Address correspondence to Rik Huiskes, Eindhoven University of Technology, Biomedical Engineering, Materials Technology, PO Box 513, WH 4.131, 5600 MB Eindhoven, The Netherlands. Electronic mail: h.w.j.huiskes@tue.nl magnitude ${ }^{7,41,43}$ in a process called 'modeling'. ${ }^{12}$ In adulthood the tissue is continuously renewed by the same cells in a process called 'remodeling'. ${ }^{13}$ In Huiskes et al. ${ }^{16}$ we proposed a theory for modeling and remodeling of trabecular structures as governed by external forces. It is based on the assumption that osteocytes within the bone tissue translate the mechanical signals they experience into biochemical messengers that are transducted through the canalicular network to the trabecular surface. ${ }^{4,8,20,21,24,27,29,37}$ At the bone surface, osteoblasts are recruited from the environment or by reactivation of lining cells ${ }^{6,10}$ in order to form bone relative to the total amount of stimulus they receive. Osteoclasts are assumed to be recruited by osteocyte apoptosis due to microdamage or cracks. ${ }^{3,30,31,39}$ We assumed that, due to daily loading conditions, microcracks and damage occur at spatially random locations, e.g., they can occur anywhere at any time. The theory is summarized in the regulation scheme depicted in Fig. 1. Our theory describes the coupling between formation and resorption as an effect of mechanical stress transfer, without specification of the regulatory biochemical factors involved, although these are implicitly assumed. This is illustrated in Fig 2. Applying $2 \mathrm{D}$ computer simulation methods we showed that this theory provides a qualitative explanation for both modeling and remodeling. ${ }^{16,34}$ We later studied the theory using a 3D finite element analysis (FEA) computational model and showed that it explains growth and maintenance of 3D trabecular-like architectures with realistic physiological and morphological characteristics. Also the adaptation of these structures to alternative loading conditions, and the morphological effects of osteoporosis and medical intervention, could be explained. ${ }^{35,36}$

A basic assumption in our theory concerns the mechanosensory and signaling functions assigned to osteocytes. ${ }^{4,8}$ The precise nature of the mechanisms by which osteocytes translate mechanical signals into bone-formation stimuli is unknown. Previously, we used the strain-energy-density (SED) rate as the relevant osteocyte signal. For the present study, we investigated whether other stress and strainrelated signals are likely to produce realistic results as well. That alternative choices of the osteocyte stimulus signal 


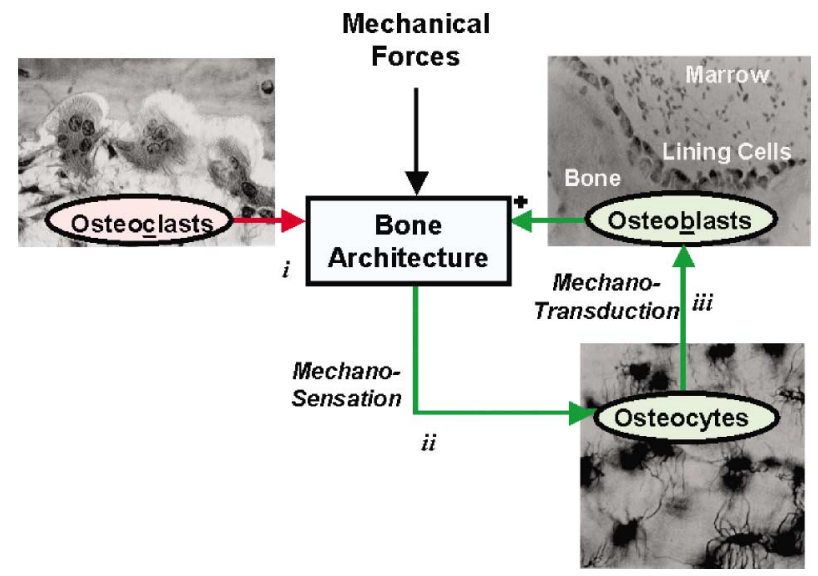

FIGURE 1. The assumed metabolic regulatory mechanisms: (i) Osteoclasts resorb bone on trabecular surface locations where microdamage occurs, attracted by apoptotic osteocytes; in the computations the sites are randomly selected, to a specified percentage per iteration (month). (ii) Osteocytes locally sense a mechanical signal due to external load transfer through the architecture; the signal is transferred to the trabecular surface, where locally (iii) osteoblasts are recruited from bone tissue. ${ }^{16,34-36}$

may affect the results considerably is obvious as the precise distribution of the mechanical signals throughout the structure can differ significantly (Fig. 3).

The fundamental issue behind the choice of the stimulus signal is whether (re)modeling signals originate in the osteocytes themselves or whether they are an effect of increased
Undeformed situation

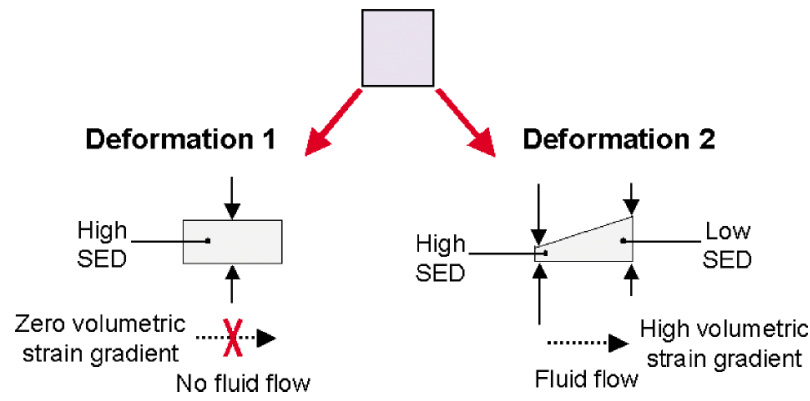

FIGURE 3. A conceptual scheme showing the different effects of mechanical variables and their gradients, specified for SED. $S E D$ produces a local load. VS-gradient produces an incentive for flow.

flow through the osteocyte network. If the signals originate in the osteocytes themselves, they could be triggered by the osteocyte lacunar stress and strain concentrations, which can be 15 times higher than the tissue (continuum) level ones. $^{2,29}$ In this case the time-derivatives of (SED), maximal principal strain (MPS) or volumetric strain (VS) could be relevant controlling variables.

However, it was also found that osteocytes are sensitive to fluid flow, ${ }^{20}$ so it was proposed that flow through the canalicular network is the actual trigger for metabolism. ${ }^{4}$ If fluid flow in the osteocytic network is assumed to cause anabolic signaling, the time-derivatives of the spatial gradients of SED, MPS, and VS could be more realistic candidates

\section{Indirect osteoblast-osteoclast coupling through mechanics}

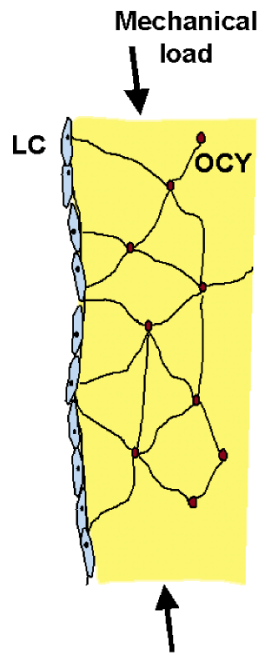

Homeostasis

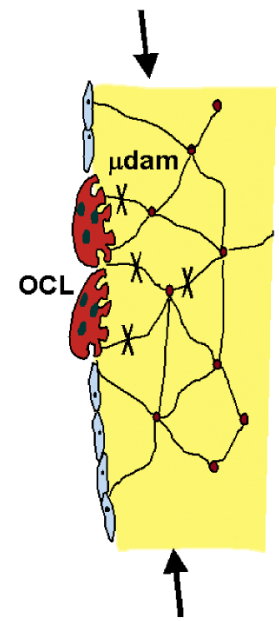

Microdamage triggers osteoclasts

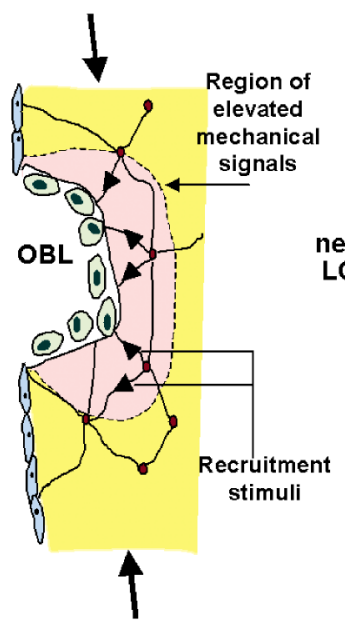

Osteocytes recruit Osteoblasts

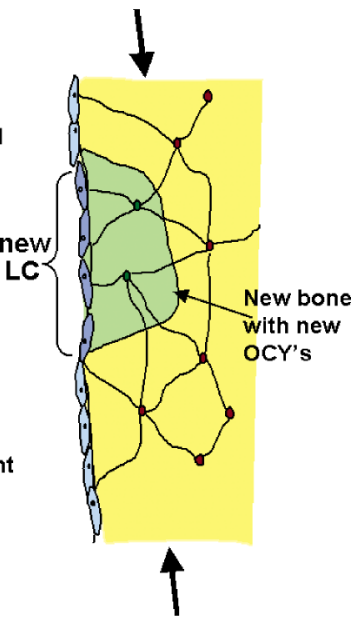

Homeostasis

FIGURE 2. During remodeling osteoclasts are attracted toward the trabecular surface due to microdamage. They produce a resorption lacunae resulting in local stress and strain concentrations surrounding the resorption cavity due to mechanical load transfer. Consequently osteocytes sense higher mechanical signals and recruit osteoblasts that form bone until the resorption cavity is filled. Some of the osteoblasts are encapsulated in the tissue matrix and differentiate to osteocytes. Other osteoblasts become inactive lining cells that cover the bone surface. Finally the homeostatic configuration is restored. 
because tissue deformation causes fluid pressures within the lacunae, and differences, or gradients, in pressure will induce flow of fluid. ${ }^{22}$

\section{METHODS}

A summary of our theory is illustrated in the regulation scheme depicted in Fig. 1. Mathematical equations were introduced to quantify relationships. ${ }^{16,34}$ The change in bone mass at a particular trabecular surface location $x$ at time $t$ is determined by

$$
\frac{\mathrm{d} m_{\mathrm{tot}}(x, t)}{\mathrm{d} t}=\frac{\mathrm{d} m_{\mathrm{bl}}(x, t)}{\mathrm{d} t}-\frac{\mathrm{d} m_{\mathrm{cl}}(x, t)}{\mathrm{d} t}
$$

with osteoblast bone formation $\mathrm{d} m_{\mathrm{bl}}(x, t) / \mathrm{d} t$ and osteoclast bone resorption $\mathrm{d} m_{\mathrm{cl}}(x, t) / \mathrm{d} t$.

Osteoblast activity at the trabecular surface is controlled by osteocyte bone-formation stimuli. For a total stimulus $P\left(\mathrm{~mol} \mathrm{~mm} \mathrm{~m}^{-2} \mathrm{day}^{-1}\right)$ that exceeds a certain threshold value $k_{t r}\left(\mathrm{~mol} \mathrm{~mm}^{-2} \mathrm{day}^{-1}\right)$ we assume osteoblast tissue formation according to

$$
\frac{\mathrm{d} m_{\mathrm{bl}}(x, t)}{\mathrm{d} t}=\tau\left(P(x, t)-k_{\mathrm{tr}}\right),
$$

where $\tau\left(\mathrm{mm}^{5} \mathrm{~mol}^{-1}\right)$ is a proportionality factor that regulates the formation rate relative to the formation stimulus. All osteocytes $N$ within the influence region contribute to the bone formation stimulus $P$ on trabecular surface location $x$, depending on their mechanosensitivity $\mu_{i}$, their distance $d$ to surface location $x$ and the signal $R$ (SED rate in our original theory) the osteocytes sense in their location $x_{i}$, hence

$$
\begin{aligned}
P(x, t) & =\sum_{i=1}^{N} f\left(x, x_{i}\right) \mu_{i} R\left(x_{i}, t\right), \text { with } \\
f\left(x, x_{i}\right) & =\mathrm{e}^{-d\left(x, x_{i}\right) / D}
\end{aligned}
$$

where $f\left(x, x_{i}\right)$ is an exponential function that describes the signal intensity relative to distance $d$ and a decay parameter $D$.

Osteoclast bone resorption is described by

$$
\frac{\mathrm{d} m_{\mathrm{cl}}(x, t)}{\mathrm{d} t}=-r_{\mathrm{cl}},
$$

where $r_{\mathrm{cl}}\left(\mathrm{mm}^{3}\right.$ day $\left.^{-1}\right)$ represents a stochastic function that describes that portions of tissue are removed from the surface at spatially random locations.

To determine the stress-strain distribution in the structures we used (FEA) for a domain divided in cubic voxels. The bone tissue within a voxel was assumed isotropic and linear elastic, with material properties depending on its density value $m$, according to 9,27

$$
E=E_{\max } m^{\gamma} .
$$

where the maximal elastic modulus $E_{\max } \mathrm{MPa}$ and exponent $\gamma$ are constants.
For force-induced remodeling the signal $R$ represented the time-derivatives of either the $\operatorname{SED}=1 / 2 \sigma: \varepsilon$, the MPS $=\max \left(\varepsilon_{i}\right)$, or the VS $=\varepsilon_{1}+\varepsilon_{2}+\varepsilon_{3}$. These values were determined in the center of each voxel. For the simulations that consider flow-induced remodeling, $R$ represented the time-derivatives of the gradients of these signals. The VS-gradient $\psi_{i}$ in voxel $i$ was determined by

$$
\psi_{i}=\sqrt{e_{i, x}^{2}+e_{i, y}^{2}+e_{i, z}^{2}},
$$

where $e$ is the VS and $e_{i, x}, e_{i, y}$ and $e_{i, z}$ are its gradients in voxel $i$ in $x, y$ and $z$ directions, respectively, according to

$$
\begin{aligned}
e_{i, x} & =\frac{\partial e_{i}}{\partial x}=\frac{e_{i+1}-e_{i-1}}{2 h} \text { for voxels } 1<i<N \\
e_{1, x} & =\frac{\partial e_{1}}{\partial x}=\frac{-3 e_{1}+4 e_{2}-e_{3}}{2 h} \\
e_{N, x} & =\frac{\partial e_{N}}{\partial x}=\frac{e_{N-2}-4 e_{N-1}+3 e_{N}}{2 h}
\end{aligned}
$$

with $h$ the spatial resolution and $N$ the number of voxels in $x$-direction. Gradients in $y$ and $z$ directions are determined similarly. The SED-gradients and MPS-gradients were computed using the same procedure. In those cases $e$ represents the SED and MPS values, respectively.

The computer simulation models were applied to a cubic domain of $2 \times 2 \times 2 \mathrm{~mm}^{3}$, divided in $60 \times 60 \times 60$ cubic voxels. In each computation, the osteocytes were assumed to respond to the relevant mechanical variable. They were assigned the calculated values in the center of the voxel in which they were located. The mechanosensitivity factor $\mu_{i}$ was set to the value relevant for the mechanical variable concerned (Table 1). Formation stimuli at the trabecular surface are all in the same range for the chosen values for the different mechanical variables. Changes in these values have the same effect as changes in the loading magnitudes.

Other parameter settings were similar to those used

\begin{tabular}{|c|c|}
\hline $\begin{array}{l}\text { Osteocytes } \\
\text { susceptible to }\end{array}$ & Sensitivity $\mu$ \\
\hline SED & $1.0\left[\mathrm{nmol} \mathrm{mm} \mathrm{m}^{-2}\right.$ day $\left.^{-1}\left(\mathrm{~J}^{-1} \mathrm{~mm}^{3} \mathrm{~s}\right)\right]$ \\
\hline SED gradient & $4.00 \times 10^{-5}\left[\mathrm{nmol} \mathrm{mm} \mathrm{mm}^{-2} \mathrm{day}^{-1}\left(\mathrm{~J}^{-1} \mathrm{~mm}^{4} \mathrm{~s}\right)\right]$ \\
\hline MPS & $2.55 \times 10^{7}\left(\mathrm{nmol} \cdot \mathrm{mm}^{-2} \cdot \mathrm{day}^{-1} \cdot \mathrm{s}\right)$ \\
\hline MPS-gradient & $0.64 \times 10^{3}\left(\mathrm{nmol} \cdot \mathrm{mm}^{-2} \cdot\right.$ day $\left.^{-1} \cdot \mathrm{mm} \cdot \mathrm{s}\right)$ \\
\hline VS & $2.55 \times 10^{7}\left(\mathrm{nmol} \cdot \mathrm{mm}^{-2} \cdot\right.$ day $\left.^{-1} \cdot \mathrm{s}\right)$ \\
\hline VS-gradient & $1.27 \times 10^{3}\left(\mathrm{nmol} \cdot \mathrm{mm}^{-2} \cdot \mathrm{day}^{-1} \cdot \mathrm{mm} \cdot \mathrm{s}\right)$ \\
\hline
\end{tabular}
in earlier simulations. ${ }^{36}$ Osteocyte density was set to $44.000 \mathrm{~mm}^{-3}$, as was found by Mullender et al. in pigs, ${ }^{28}$ randomly distributed within the tissue, corresponding to approximately 6 osteocytes along the diameter of a trabecula with a thickness of $150 \mu \mathrm{m}$. The osteocyte influence distance $D=100 \mu \mathrm{m}$. The threshold for osteoblast bone

TABLE 1. Adjusted mechano-sensitivity factors in the regulatory formulas for the tested variables on which the computational analysis are based. 
formation was $k_{t r}=5.0 \times 10^{6}\left(\mathrm{nmol} \mathrm{mm}{ }^{-2} \mathrm{day}^{-1}\right)$, and the proportionality factor $\tau=1.4 \times 10^{-10}\left(\mathrm{~mm}^{5} \mathrm{nmol}^{-1}\right)$. Osteoclast recruitment frequency on the surface was set to $7.1 \times 10^{-2}$ (percent voxel ${ }^{-1} \mathrm{day}^{-1}$ ) and the amount of bone tissue per cavity was 1.5 voxels, i.e. $5.6 \times 10^{-5}\left(\mathrm{~mm}^{3}\right) .{ }^{11}$ The iteration time step was set to 1 month. The maximal elastic modulus per voxel was set to $E_{\max }=5.0 \mathrm{GPa}$, the Poison ratio $v=0.3$, and the exponent $\gamma=3 .{ }^{9}$ To impose external forces, plates with a thickness of one voxel were added at the surfaces of the cubic domain, disconnected at the ribs of the cube in order to avoid stress shielding. ${ }^{34}$ The plates were given material properties as fully mineralized bone tissue. They do not participate in the remodeling process, i.e. they do not adapt. For the lower plate we repressed 6 degrees of freedom. The $x$-, $y$-, and $z$-coordinate for one corner in the origin, the $x$ - and $y$-coordinate for the second corner on the $x$-axis, and the $z$-coordinate of the second corner on the $y$-axis. As a mechanical load we imposed a distributed harmonic cyclic stress with $1(\mathrm{~Hz})$ and an amplitude of 2.0 (MPa). This load was compressive in the vertical direction and tensile in the horizontal directions. We assumed that osteocytes respond to the maximal rate of change of the proposed mechanical signals during one loading cycle. We neglected inertia so that these values could be determined using static FE analysis. ${ }^{34}$

Several computational series were performed: (1) Simulated growth (modeling) from an initial fine, porous structure toward a mature homeostatic 3D trabecular-like structure. Once this homeostatic structure is obtained no more-gross architectural changes occurred, but remodeling continued. (2) The mature structure was subjected to $50 \%$ reduced loads and to $50 \%$ increased loads to investigate the effect of alternative loading magnitudes. (3) The structure was also subjected to a $20^{\circ}$ rotated load to investigate whether the mature structure realigns accordingly. During the simulations, we monitored the developments in morphology, volume fraction (VF) and the distribution of the signals sensed by osteocytes. For the homeostatic configurations, we determined trabecular thickness (Tr.Th), trabecular spacing (Tr.Sp), and trabecular number (Tr.N) according to the parallel plate model. ${ }^{32}$ In addition to we determined the remodeling rates (net-full turnover). The 'remodeling space'- the total volume of unfilled resorption cavities-was determined by prolonging the simulation with osteoclast-resorption completely inhibited. The morphologic and metabolic effects of increased and reduced external loads were also studied.

\section{RESULTS}

An example of the adaptive effects in a simulation, from the initial, refined morphology with thin trabeculae [Fig. 4(A)] to maturity, is demonstrated in Fig. 4(B), relative to VS-gradient as the mechanical feedback variable. With

\section{Volumetric strain gradient}

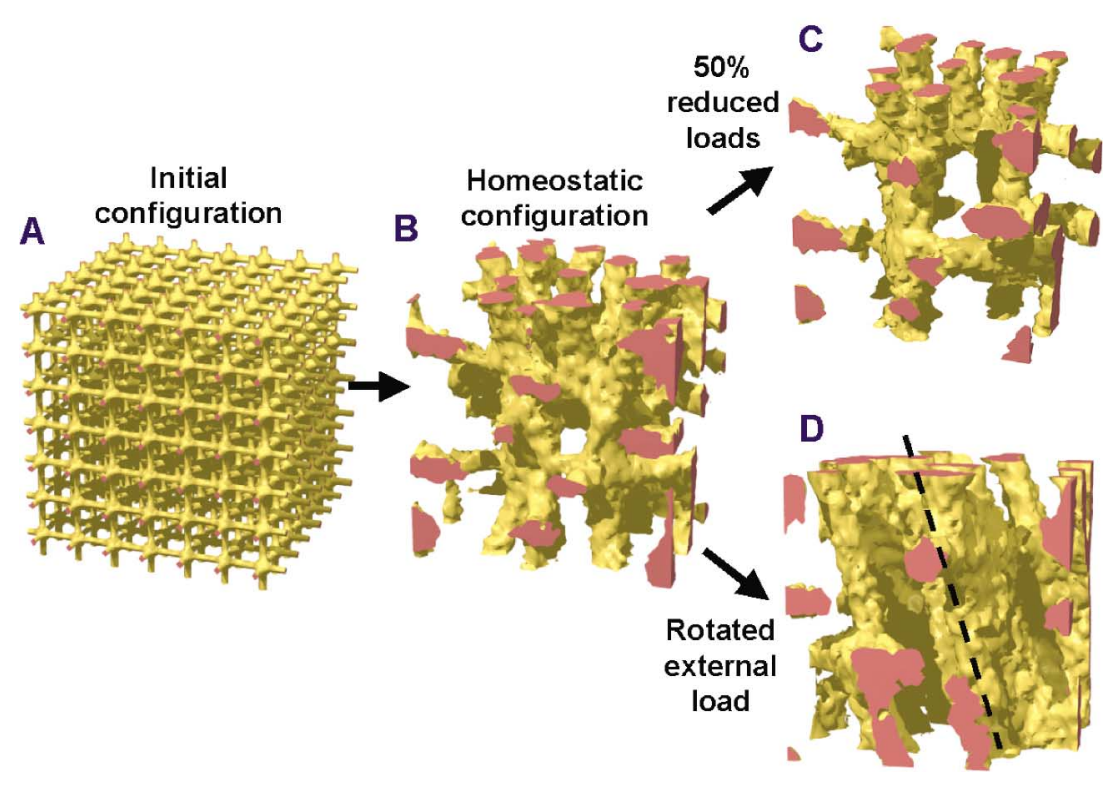

FIGURE 4. Morphological results of the simulation using VS-gradient as the controlling variable. Starting from a refined initial configuration, representing bone in the post mineralized fetal stage (A) the structure developed a mature structure in approximately 10 simulated years in modeling, with trabecuale aligned to the load orientations. (B) Henceforth the structure was maintained; no more large architectural changes occurred, although osteoclast resorption and osteoblast repair continued in remodeling. (C) The structure adapted to $50 \%$ reduced loads by trabecular thinning and loss of complete trabeculae. (D) Rotating the external load led to reorientation of the trabeculae to the new loading direction, completed after about 12 simulated years. (The trabecular surface was smoothed for clarity of the images.) 

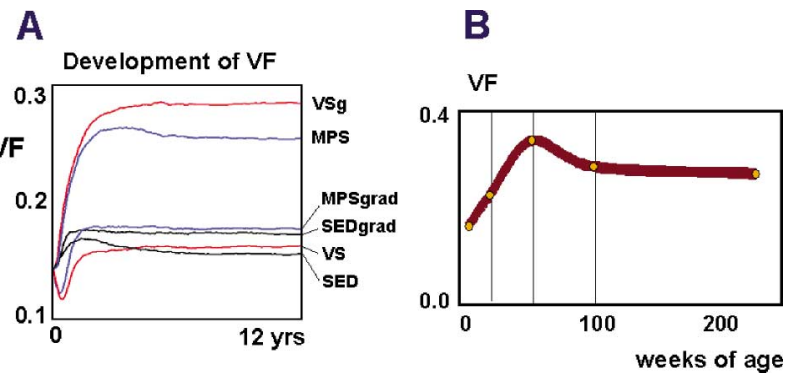

FIGURE 5. (A) Development of volume fraction (VF) during the simulation for the different controlling variables. Only the simulations using SED and MPS as controlling variables reproduced a clear overshoot in bone mass (VF) as it occurs around puberty. (B) Development of volume fraction as found in a study of bone growth in pigs. ${ }^{38}$

proceeding time the structure became coarser until finally homeostasis was reached, with less, but thicker, trabeculae, aligned with the external loads. Initially VF rose sharply in modeling and later stabilized to a final, mature value of 0.28 [Fig. 5(A)]. The overshoot in VF that was observed in morphological studies of bone development in growing pigs $^{38}$ did not occur, however. From that stage on formation and resorption were balanced (remodeling). Tr.Th was on the order of $300 \mu \mathrm{m}$ and the remodeling rate was such that the net total bone mass was replaced in 5.7 years. The remodeling space was $21 \%$. The average VS-gradient sensed by osteocytes was large initially $\left(200 \mathrm{~m}^{-1}\right)$, but reduced to $110 \mathrm{~m}^{-1}$ in the homeostatic configuration, illustrating the mechanical 'shape optimization' that had taken place.
We also investigated the effects of alternative loads on the homeostatic configuration. A load reduction to $50 \%$, in the VS-gradient based simulation, caused loss of bone tissue by trabecular thinning and loss of connectivity toward a VF of 0.15 [Fig. 4(C)]. Increasing the loading magnitude by $50 \%$ increased VF to 0.39 , but no new trabeculae were formed. Besides adaptation to alternative loading magnitudes, the simulations predicted that the structure realigns to alternative loading directions. Rotating the external load by $20^{\circ}$ resulted in a sharp rise in VF that gradually decreased until after 20 simulated years [Fig. 4(D)].

The simulations based on the other mechanical loading variables (SED, SED-gradient, MPS, MPS-gradient, and VS), produced largely similar mature morphologies. In all cases 3D trabecular-like architectures were formed (Fig. 6), with trabeculae aligned to the external loading orientations. The VFs were between 0.16 and 0.28 (Table 2). Average Tr.N varied between 0.64 and $1.51 \mathrm{~mm}^{-1}$, Tr.Sp between 500 and $1300 \mu \mathrm{m}$ and average Tr. Th between 133 to $300 \mu \mathrm{m}$ (Table 2). Remodeling rate, expressed in years of net full turnover varied from 3.8 to 5.7 years and remodeling space was between 0.08 and 0.24 (Table 2). Bone mass reduced by $44-50 \%$ (Table 2) — by trabecular thinning and loss of connectivity - after reducing the external loads by $50 \%$. Increasing the loads by $50 \%$ produced bone-mass increases between 33 and $56 \%$, by expansion of Tr.Th (Table 2).

The values of the mechanical variables in each simulation converged to similar spatial frequency distributions in the homeostatic (mature) state. The coefficients of variation $(\mathrm{COV})$, i.e., standard deviation to mean ratio, is a measure

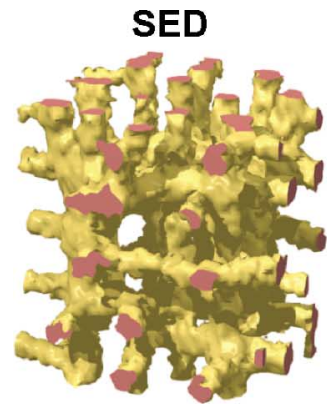

SED grad.

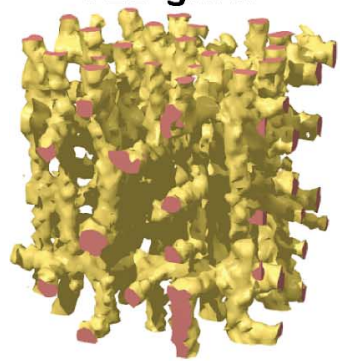

max. princ. str.

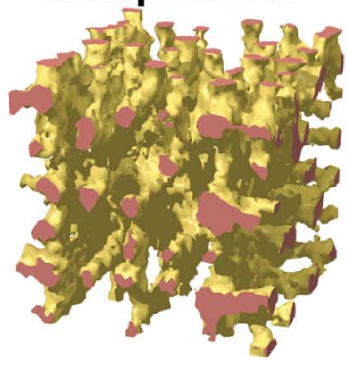

max. princ. str. grad.

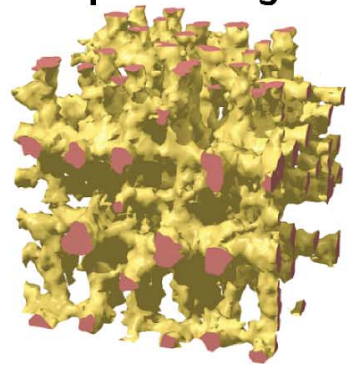

volumetric str.

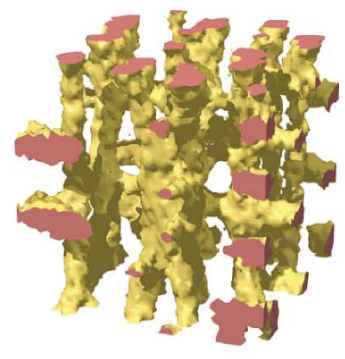

volumetric str. grad.

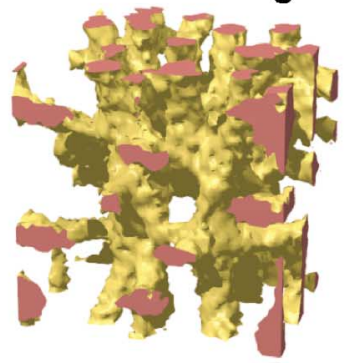

FIGURE 6. Homeostatic trabecular morphologies as a result of the different controlling mechanical variables tested. 
TABLE 2. Morphological results of the computational analyses with the 6 mechanical variables tested: VF, Tr.N, average Tr.Sp, average Tr.Th, resorption rate (the number of years required for net full turnover), the remodeling space and the COV of the mechanical signal sensed, all in the homeostatic configurations. Additionally, the loss/gain of bone mass in response to $50 \%$ reduced, respectively increased loads, both relative to the homeostatic morphology. Data from literature ${ }^{15,18,19,31}$ are added in the last row for comparison.

\begin{tabular}{|c|c|c|c|c|c|c|c|c|c|}
\hline Osteocytes susceptible to & VF & $\operatorname{Tr} . \mathrm{N}\left(\mathrm{mm}^{-1}\right)$ & $\operatorname{Tr} . S p(\mu \mathrm{m})$ & Tr.Th $(\mu \mathrm{m})$ & $\begin{array}{l}\text { Resorption rate } \\
\text { net full } \\
\text { turnover (years) }\end{array}$ & $\begin{array}{l}\text { Resorption } \\
\text { space }\end{array}$ & signal COV & $\mathrm{F} 50 \% \downarrow$ & $\mathrm{F} 50 \% \uparrow$ \\
\hline SED & 0.16 & 0.96 & 880 & 166 & 4.2 & 0.09 & 1.23 & $-50 \%$ & $+56 \%$ \\
\hline SED gradient & 0.18 & 1.35 & 610 & 133 & 3.8 & 0.08 & 1.17 & $-50 \%$ & $+39 \%$ \\
\hline Max. principal strain & 0.25 & 1.51 & 500 & 166 & 4.2 & 0.24 & 1.50 & $-44 \%$ & $+36 \%$ \\
\hline Max. principal strain grad & 0.18 & 1.08 & 760 & 166 & 4.1 & 0.13 & 1.36 & $-44 \%$ & $+33 \%$ \\
\hline VS & 0.17 & 0.64 & 1.300 & 266 & 4.8 & 0.22 & 1.63 & $-47 \%$ & $+47 \%$ \\
\hline VS grad. & 0.28 & 0.93 & 770 & 300 & 5.7 & 0.21 & 1.50 & $-46 \%$ & $+43 \%$ \\
\hline Data from literature & $0.15-0.25$ & $0.70-2.00$ & $400-1100$ & $100-200$ & $3-5$ & $0.03-0.05$ & - & - & - \\
\hline
\end{tabular}

for stability as low values relate to uniform loading distributions whereas high values relate to inhomogeneous loading. COV values varied between 1.17 and 1.63 (Table 2). Simulations using SED and its gradient had the lowest (COV). This indicates that osteoclast-resorption cavities were repaired more rapidly. This fits with the observation that the remodeling space for SED-based simulations was smaller (Table 2). Development of total bone mass (VF) during the simulation to maturity over time was very similar as well in most simulations. Only the simulations using SED and MPS as mechanical variables reproduced the typical overshoot in VF at around puberty [Fig. 5(B)], as it was found in morphological bone modeling — growth—-studies in pigs. ${ }^{33}$

\section{DISCUSSION}

We developed a computational framework for strainrelated trabecular bone remodeling and adaptation. ${ }^{16,34} \mathrm{We}$ already showed how it can be applied in the search for relationships suitable to explain trabecular deterioration in disused or postmenopausal osteoporotic bone. ${ }^{35,36}$ For this study, we asked the question whether mechanical variables other than SED-rate could be more realistic or effective in simulating remodeling and adaptation. In particular, we were interested in comparing the effects of the mechanical variables themselves-as variables representing the actual loads on the osteocyte 'sensors'- to the effects of their gradients, as related to the mechanical effects on fluid flow in the canalicular network. We found that all six loading variables studied produced reasonable, trabecularlike morphologies. Moreover, for all variables, adaptive behavior persisted, despite changes in loading magnitude and direction. Elevated external loads increased Tr.Th, ${ }^{17,23}$ and reduced loads caused trabecular thinning and loss of connectivity. ${ }^{26}$ Alternative loading directions caused trabeculae to realign accordingly. This is analogous to what is observed in growing bone, ${ }^{38}$ after fracture healing ${ }^{41}$ and in relation with implant incorporation. ${ }^{14}$ However, according to Bertram and Swartz ${ }^{1}$ it was never found to occur after redirection of loads in healthy, mature bone. One explanation for this controversy may be that-according to our predictions - it takes a relatively long time for the structure to adapt, whereas animal experiments on this question were never extended so long.

The question is now how these alternative signal formulations could be discriminated in their effects. For that purpose, we first compared actual morphological data predicted to literature data of the VF, Tr.N, Tr.Sp, Tr.Th, net full turnover rate, and remodeling space. Comparing these values with the results of the computations (Table 2) eliminates all but SED, SED-gradient, and MPS-gradient as suitable variables; although each of them had remodeling-space values up from about two times higher than what is normal. ${ }^{19}$

Another criterion for realistic behavior is the overshoot in VF in puberty, found in morphological studies in pigs (Fig. 5). ${ }^{38}$ This was only reproduced for SED and MPS as regulating variables. Furthermore, we compared the efficacy of the different variables: which produced the leastbone mass (VF) for a given loading set. SED appears most effective to that criterion. SED and its gradient were also the variables producing the most homogenous distributions of mechanical signals in their homeostatic structures, with COV at 1.23 and 1.17 - compared to the others at 1.36-1.63, which makes them the most effective ones.

Safety against fracture is also an evolutionary issue of importance. Short 'net full turnover' (Table 2) is an asset in this respect, as it implies swift repair of microcracks, and so is a low 'remodeling space,' as it reduces the amount of notches at any time, and hence the probability of fatigue failure. Again SED and SED-gradient come out as the most advantageous relative to these criteria.

Finally, adaptability to external loading is an evolutionary issue. It is metabolically advantageous when a temporary reduction in external loads has a mild response in bone loss and, conversely, increases in load swiftly add bone. It appears that our theory is most sensitive to SED as loading variable, although the differences with other variables are not so large in this respect. 
Compared to these criteria, with 'closeness to reality' as the most prominent asset, and 'efficacy' as the second, SED appears the most attractive variable. Certainly VS and its gradient seem less attractive, according to these criteria.

Hence, it seems reasonable to employ SED as the loading variable for further investigative computations concerning trabecular bone (re)modeling. However, the results do not prove that osteocytes respond to local loads in a direct, mechanical sense, as opposed to being sensitive to fluid flow, generated by stress on the osteocytic canalicular network as a whole. The reason for this is basically that the theory employed is extremely robust. This robustness is caused by the negative feedback between tissue loading and bone formation. We saw that whatever the mechanical signal, the theory produces reasonable trabecular structures. Although we did not investigate this, it might be that equally realistic morphologies and metabolic parameters could be generated by all signals investigated, by variation of the process parameters for which a realistic value is not known-like osteocyte sensitivity, distance decay parameter, proportionality factor, or others. More information could only be obtained if more realistic, and refined-'mechanistic'-models ${ }^{20,22,40,42}$ for signal transduction would be included in the theory. This would also imply the use of a more realistic description for the dynamic external forces. Computational restrictions defy that, at the moment.

Although the theory is restricted by the use of lumped, conceptual variables, and parameters, it does include both mechanical and metabolic descriptions of the relevant processes, however, crudely the latter are represented. This makes the model a suitable tool to investigate relationships between mechanical forces, its metabolic effects and bone architecture. The results show, again, that coupling of osteoclast resorption to osteoblast bone formation, through the effects of stress concentrations ('notching') around resorption lacunae $e^{5,16,25,33}$ is a viable hypothesis. And finally, the predictions of the theory are quite insensitive to the refinement of its parametric and signal representations, as shown here once more-hence, attractive in an evolutionary sense.

\section{REFERENCES}

${ }^{1}$ Bertram, J. E., and S. M. Swartz. The 'law of bone transformation': A case of crying Wolff? Biol. Rev. Camb. Philos. Soc. 66:245-273, 1991.

${ }^{2}$ Brand, R. A., C. M. Stanford, and D. P. Nicolella. Primary adult human bone cells do not respond to tissue (continuum) level strains. J. Orthop. Sci. 6(3):295-301, 2001.

${ }^{3}$ Bronckers, A. L. J. J., W. Goei, G. Luo, G. Karsenty, R. N. D'Souza, D. M. Lyaruu, and E. H. Burger. DNA fragmentation during bone formation in neonatal rodents assessed by transferase-mediated end labeling. J. Bone Miner. Res. 11:12811291, 1996.

${ }^{4}$ Burger, E. H., and J. Klein-Nulend. Mechanosensory transduction in bone-role of the lacuno-canalicular network. FASEB J. 13:S101-S112, 1999.
${ }^{5}$ Chambers, T. J. The direct and indirect effects of estrogen on bone formation. Adv. Organ. Biol. 5B:627-638, 1998.

${ }^{6}$ Chow, J. W., A. J. Wilson, T. J. Chambers, and S. W. Fox. Mechanical loading stimulates bone formation by reactivation of bone lining cells in 13-week-old rats. J. Bone Miner. Res. 13:1760-1767, 1998.

${ }^{7}$ Courteix, D., E. Lespessailles, S. Loiseau Peres, P. Obert, P. Germain, and C. L. Benhamou. Effects of physical training on bone mineral density in prepubertal girls: a comparative study between impact-loading and non-impact-loading sports. Osteoporos. Int. 8:152-158, 1998.

${ }^{8}$ Cowin, S. C., L. Moss-Salentijn, and M. L. Moss. Candidates for the mechanosensory system in bone. J. Biomech. Eng. 113:191197, 1991.

${ }^{9}$ Currey, J. D. The effect of porosity and mineral content on the Young's modulus of elasticity of compact bone. J. Biomech. 21:131-139, 1988.

${ }^{10}$ Dobnig, H., and R. T. Turner. Evidence that intermittent treatment with parathyroid hormone increases bone formation in aged rats by activation of bone lining cells to osteoblasts. Endocrinology 136:3632-3638, 1995.

${ }^{11}$ Eriksen, E. F., and M. Kassem. The Cellular basis of bone remodeling. In: Triangle 31 Sandoz J. of Med. Sc., The changing architecture of the skeleton. pp 45-57, 1992.

${ }^{12}$ Frost, H. M. Skeletal structural adaptations to mechanical usage (SATMU): 1. Redefining Wolff's Law: The bone modelling problem. Anat. Rec. 226:403-413, 1990.

${ }^{13}$ Frost, H. M. Skeletal structural adaptations to mechanical usage (SATMU): 2. Redefining Wolff's Law: The remodeling problem. Anat. Rec. 226:414-422, 1990.

${ }^{14}$ Guldberg, R. E., M. Richards, N. J. Caldwell, C. L. Kuelske, and S. A. Goldstein. Mechanical stimulation of tissue repair in the hydraulic bone chamber. J. Bone Miner. Res. 12:1295-1302, 1997.

${ }^{15}$ Han, Z. H., S. Palnitkar, D. S. Rao, D. Nelson, and A. M. Parfitt. Effects of ethnicity and age or menopause on the remodeling and turnover of iliac bone: Implications for mechanisms of bone loss. J. Bone Miner. Res. 12:498-508, 1997.

${ }^{16}$ Huiskes, R., R. Ruimerman, G. H. van Lenthe, and J. D. Janssen. Effects of mechanical forces on maintenance and adaptation of form in trabecular bone. Nature 405:704-706, 2000.

${ }^{17}$ Jee, W. S. S., and X. J. Li. Adaptation of cancellous bone to overloading in the adult rat: A single photon absorptiometry and histomorphometry study. Anat. Rec. 227:418-426, 1990.

${ }^{18} \mathrm{Jee}, \mathrm{W}$. S. S. Integrated bone tissue physiology: Anatomy and physiology. In: Bone Mechanics Handbook, edited by S. C. Cowin. London: CRC Press, 2001, pp. 1.1-1.68.

${ }^{19}$ Kanis, J. A. Osteoporosis, Blackwell Healthcare Communications, 1997.

${ }^{20}$ Klein-Nulend, J., A. van der Plas, C. M. Semeins, N. E. Ajubi, J. A. Frangos, P. J. Nijweide, and E. H. Burger. Sensitivity of osteocytes to biomechanical stress in vitro. FASEB J. 9:441-445, 1995.

${ }^{21}$ Knothe Tate, M. L., and M. B. Schaffler. Loss of Osteocyte Integrity Colocolizes with Bone Resorption Following Disuse. Trans. 48th Ann. meeting of the Orthop Res Society, Dallas, Texas, 2002.

${ }^{22}$ Kufahl, R. H., and S. Saha. A theoretical model for stressgenerated fluid flow in the canaliculi-lacunae network in bone tissue. J. Biomech. 23:171-180, 1990.

${ }^{23} \mathrm{Li}$, C. Y., D. Laudier, and M. B. Schaffler. Remobilization restores cancellous bone mass but not microarchitecture after long term disuse in older adult dogs. Trans. 49th Ann. meeting of the Orthop Res Society, New Orleans, LA, 2003. 
${ }^{24}$ Martin, R. B. Towards a unifying theory of bone remodeling. Bone 26:1-6, 2000.

${ }^{25}$ McNamara, L. M., J. C. van der Linden, H. Weinans, P. J. Prendergast. High stresses occur in bone trabeculae under low loads A study using micro-serial sectioning techniques and finite element analysis. Proceedings of the 13th Conference of the ESB, Wroclow, Poland, 2002.

${ }^{26}$ Mosekilde, L. Consequences of the remodeling process for vertebral trabecular bone structure: A scanning electron microscopy study (uncoupling of unloaded structures). Bone Miner. 10:1335, 1990.

${ }^{27}$ Mullender, M. G., and R. Huiskes. A proposal for the regulatory mechanism of Wolff's law. J. Orthop. Res. 13:503-512, 1995.

${ }^{28}$ Mullender, M. G., R. Huiskes, H. Versleyen, and P. Buma. Osteocyte density and histomorphometric parameters in cancellous bone of the proximal femur in five mammalian species. $J$. Orthop. Res. 14:972-979, 1996.

${ }^{29}$ Nicolella, D., and J. Lankford. Strain Concentration Effects of Osteocyte Lacunae. Trans. 48th Ann. meeting of the Orthop Res Society, Dallas, Texas, 2002.

${ }^{30}$ Noble, B. S., H. Stevens, N. Loveridge, and J. Reeve. Identification of apoptotic changes in osteocytes in normal and pathological human bone. Bone 20:273-182, 1997.

${ }^{31}$ Parfitt, A. M., C. H. E. Mathews, A. R. Villanueva, and M. Kleerekoper. Relationships between surface, volume, and thickness of iliac trabecular bone in aging and in osteoporosis. J. Clin. Invest. 72:1396-1409, 1983.

${ }^{32}$ Parfitt, A. M., M. K. Drezner, F. H. Glorieux, J. A. Kanis, H. Malluche, P. J. Meunier, S. M. Ott, and R. R. Recker. Bone histomorphometry: Standardization of nomenclature, symbols, and units. Report of the ASBMR histomorphometry nomenclature committee. J. Bone Miner. Res. 2:595-610, 1987.

${ }^{33}$ Rodan, G. A. Mechanical loading, estrogen deficiency, and coupling of bone formation to bone resorption. J. Bone Miner. Res. 6:527-530, 1991.
${ }^{34}$ Ruimerman, R., R. Huiskes, G. H. van Lenthe, and J. D. Janssen. A computer-simulation model relating bone-cell metabolism, to mechanical adaptation of trabecular bone. Comput. Methods Biomech. Biomed. Engin. 4:433-448, 2001.

${ }^{35}$ Ruimerman, R., P. Hilbers, B. van Rietbergen, and R. Huiskes. Indirect osteoblast-osteoclast coupling through mechanics explains elevated osteoblastic bone formation as a response to increased osteoclastic activity. Trans. 49th Ann. meeting of the Orthop Res Society, New Orleans, LA, 2003.

${ }^{36}$ Ruimerman, R., P. Hilbers, B. van Rietbergen, and R. Huiskes. A theoretical framework for strain-related trabecular bone maintenance and adaptation. J. Biomech. In press.

${ }^{37}$ Skerry, T. M., L. Bitensky, J. Chayen, and L. E. Lanyon. Early strain-related changes in enzyme activity in osteocytes following bone loading in vivo. J. Bone Miner. Res. 4:783-788, 1989.

${ }^{38}$ Tanck, E., J. Homminga, G. H. van Lenthe, and R. Huiskes. Increase in bone volume fraction precedes architectural adaptation in growing bone. Bone 28:650-654, 2001.

${ }^{39}$ Verborgt, O., G. J. Gibson, and M. B. Schaffler. Loss of osteocyte integrity in association with microdamage and bone remodeling after fatigue in vivo. J. Bone Miner. Res. 15:60-67, 2000.

${ }^{40}$ Weinbaum, S., S. C. Cowin, and Y. Zeng. A model for the excitation of osteocytes by mechanical loading-induced bone fluid shear stresses. J. Biomech. 27:339-360, 1994.

${ }^{41}$ Wolff, J. Das Gesetz der Transformation der Knochen. Berlin A. Hirchwild (1892) Translated as: The Law of Bone Remodeling edited by Maquet P., and R. Furlong, Berlin: Springer-Verlag, 1986.

${ }^{42}$ You, L., S. C. Cowin, M. B. Schaffler, and S. Weinbaum. A model for strain amplification in the actin cytoskeleton of osteocytes due to fluid drag on pericellular matrix. J. Biomech. 34:13751386, 2001.

${ }^{43}$ Zerwekh, J. E., L. A. Ruml, F. Gottschalk, and C. Y. C. Pak. The effects of twelve weeks of bed rest on bone histology, biochemical markers of bone turnover, and calcium homeostasis in eleven normal subjects. J. Bone Miner. Res. 13:1594-1601, 1998. 